\title{
Towards sustainable food productions in Morocco: Aquaponics
}

\author{
Haytam Rharrhour ${ }^{1 *}$, Fatima Wariaghli ${ }^{1}$, Simon Goddek ${ }^{2}$, Mohamed Sadik ${ }^{3}$, Aziz El \\ Moujtahid ${ }^{4}$, Hassan Nhhala ${ }^{5}$, and Ahmed Yahyaoui ${ }^{1}$ \\ ${ }^{1}$ BIOECOGEN Laboratory, Faculty of Sciences of Rabat, Mohammed V University, 4 Avenue Ibn \\ Battouta B.P. 1014 RP, Rabat; \\ ${ }^{2}$ Mathematical and Statistical Methods (Biometris), Wageningen University, P.O. Box 16, 6700 AA \\ Wageningen, The Netherlands; \\ ${ }^{3}$ Water and Forests Department, National Hydrobiology and Fish-farming Center, Azrou 53100, \\ Morocco; \\ ${ }^{4}$ Sciences and Technologies Faculty, Soultan Moulay Slimane University, Beni-Mellal, Morocco; \\ ${ }^{5}$ Faculty of Science and Technics, University of Abdelmalek Essaadi, Ancienne Route de l'Aéroport, \\ Km 10, Ziaten. BP : 416. Tangier - Morroco.
}

\begin{abstract}
This article reviews the development potential of Aquaponics in Morocco, an emergent approach which integrates aquaculture with Hydroponics, whereby aquaculture effluent is used to fertilise plants in the hydroponic system. Aquaponics is the subject of an alternative solution to earth modern problems, linked to climate change, such as drought, soil degradation, food and water availabilities, negative impact of aquaculture on the environment, the use of chemicals and pharmaceuticals. This food production system has gained interest in the past five years, however, there is yet to be successful experiences or scientific publications in Morocco, although the economy of this country is based on two main sectors: agriculture and fisheries. The current paper was developed using a systematic, strategic and comprehensive literature review on peer reviewed publications on several themes, including aquaponics, aquaculture, hydroponics and horticulture, from 1960 to 2020. Over 59publications were reviewed and analysed. The review found that aquaponics has gained interest in the past five years, over 500 scientific articles have been published, since 2015, with the term "Aquaponics" as title, abstract or keyword, highlighting its many advantages and major drawbacks, but unfortunately none of these publications were of Moroccan origin, which consolidates the need for a review which will scale up the importance of this technique and its development potential in Morocco.
\end{abstract}

\section{Introduction}

The economy of Morocco is principally based on fisheries and agriculture, that contribute by $2.3 \%$ and $15 \%$ to the GDP respectively [1-2]. However, these two sectors suffer from several problems, such as over exploitation of natural resources, pollution, drought and

\footnotetext{
*Corresponding author: haytam.rharrhour@um5r.ac.ma
} 
climate change. Also, demand for fish and aquaculture products in Morocco are increasing due to population growth (36 million in 2017, 39 million forecast for 2025).

The Moroccan Agricultural sector is at the centre of the national economy, having an added value of around 13.92billion USD for 2017, with an average GDP (between 2008 and 2017) exceeding 11.80 billion USD/ year. The agriculture sector remains the primary provider of jobs [2]. In rural areas, nearly three-quarters of the working population gets their income from the food industry (i.e. agriculture, forestry, and fishing). $38 \%$ of total employment, as a minimum, are offered by agricultural activities. The Moroccan agroindustry produced a total of 335 thousand tonnes (equivalent to 711Million USD) of diverse products such as fruits and vegetables, cereals, seeds, spices and more in 2017 [2]. The Moroccan fishery sector is considered an essential industry of the country, its annual production is around 1,4 million tons of fish, divided into 1.3 million tons of Coastal and artisanal fishing, 64 thousand tons of deep-sea fishing, and about twenty thousand tons of other activities such as aquaculture. The Moroccan fishery sector employs in total about120,000 fishers and about50,000 people who are working in the processing, transport, and fish trade[1]. While most commercial fisheries can be found in the south of the country.

Integrated Agriculture Aquaculture Systems (IAAS) were practised to treat aquaculture effluents. These systems were adopted to develop an emergent approach, in the past fiveyears, scientific publications about aquaponics exponentially increases since 2015 . Aquaponics is the amalgamation of two major food production sectors: aquaculture and agriculture. It is the combination of the RAS (Recirculation Aquaculture System) with hydroponics [3-4-5-6] from where name "Aquaponics" comes. It has gained interest due to its potential for supplying food security and providing local food self-sufficiency in arid areas.

Aquaponics technology is based on the coupling of RAS with hydroponics (soil-less crop culture), in which nutrient rich aquaculture effluent is used to grow plants in hydroponic system [3-4-7]. Recirculation aquaculture system "RAS" is a closed tank based fish farming system, considered as an alternative solution for water consumption by pond aquaculture [8], due to its land and water low requirements [9]. In aquaponics, RAS fish tanks are linked to hydroponic production beds, whereby plants use nutritional elements dissolved in water [3], therefore, hydroponic unit serves as abiological filter in order to purify water before sending it back to the fish tanks in a closed system context. Aquaponics is a quasi-closed food production system that produces both fish and plants without the need of chemicals and pharmaceuticals, using 90\% less water than Aquaculture and hydroponics. However, this technique has shown some drawbacks, especially coupled aquaponics systems that have a low economic profitability and inefficient nutrients availability for plants.

This paper aims to give an overview of aquaponics potential for responding to food productions environmental impact, food insecurity and inequality in its availability, poverty and water scarcity in developing countries like Morocco.

\section{Method}

The present study was developed using a systematic, strategic and comprehensive literature review on peer reviewed publications on several themes, including aquaponics, aquaculture, hydroponics and horticulture, from 1960 to 2020 on both Scopus and Google Scholar. More than 100 publications were reviewed, analysed, collected in the reference software Zotero, and classified depending on key words and year of publishing, among which we choose to work on 59 papers that were considered valuable. 


\section{Aquaponics}

\subsection{Definition}

Aquaponics is a closed-loop recirculated food production system, that uses nutrient-rich aquaculture effluent to grow plants in hydroponic systems. Aquaponics is considered an alternative sustainable solution for both aquacultural and agricultural productions, addressing water scarcity, pollution, soil erosion and degradation [4-6-7-10].Food production industries have an effect on air and water quality, ecosystem functions, and energy consumption [11]. Aquaponics is considered a model of sustainable agriculture, a newly emerging approach that combines intensive food production with waste-stream recycling and water conservation [4-7].

Considering population growth and environmental issues linked to climate change, aquaponics can cover the local demand for fish and vegetables if its basic principles are respected.

\subsection{History}

Early Asian and American civilisations used fish wastes to fertilise crops [12]; Aztecs used surrounding cities waste materials to fertilise cultivated agricultural islands known as Chinampas, while in south China, Thailand and Indonesia, rice was cultivated in combination with fish, in a sort of early aquaponics.

One of the pioneering works of aquaponics returns to The New Alchemy Institute, in East Falmouth, Massachusetts. In the late 1970s, the institute provided several publications on aquaponics [3-12], which were the seed of modern aquaponics. In 1977, [13] validated the feasibility of combining fish and plants productions in a recirculating water system, by producing ice-lettuce and tomatoes and highlighting the nitrification process. The evolution of the "flood and drain systems" adopted in backyard aquaponics comes back to the pioneering work of Mark McMurtry [3-14], in the 80s, inventor of Integrated AquaVegeculture System (IAVS). Tom and Paula Speraneo adopted, in the early 1990s, the North Carolina State University system to invent a full-size commercial-scale solar greenhouse [3].

Over the past five years, aquaponics has gained a growing interest considering its key benefits which respond to the disadvantages of aquaculture and the unsustainable use of water by agriculture.

\subsection{Aquaponics principles}

A question that needs to be asked is whether plants can assimilate fish waste? In general, fish excreta are mainly composed of ammonia [9]. Vines and wedding (1960) [15] suggested that ammonia is toxic for both plants and animals, mentioning that ammonia's toxicity is represented by its impact on the electron transport system in plants mitochondria, while [16] claims that ammonium is necessary for plants, $\mathrm{NH}_{4}{ }^{+}$ions stimulates the uptake of nitrate $\mathrm{NO}_{3}{ }^{-}$, suggesting a ratio of $75 \% \mathrm{NO}_{3}{ }^{-}$to $25 \% \mathrm{NH}_{4}{ }^{+}$.

The nitrifying bacteria, plays a vital role in aquaponic systems [3-6-7], by transforming ammonia into nitrates, the form of nitrogen used by plants [17]. This shows that aquaponics is a mini-ecosystem wherein fish, plants, and bacteria coexists in a symbiotic way. 


\subsection{Key elements}

\subsubsection{Nutrient balance}

In aquaponic systems, uneaten feed and fish excreta are the primary source of plants nutrients, which fall into two categories, based on required quantities, macronutrients and micronutrients; Carbon, hydrogen, oxygen, nitrogen, phosphorus, potassium, calcium, Sulphur and magnesium are required in large quantities, also called macronutrients, while iron, copper, zinc, manganese, molybdenum, boron, and chlorine are considered as micronutrients [18-19-20-21].

Fish tanks effluent provides both macronutrients such as ammonia, nitrate, nitrite, phosphorus, potassium, and micronutrients to produce hydroponic plants, however, one of the limitations with aquaponics is iron deficiency, which is needed for both plants and fish growth [10]. Aquaponic systems are often nutrient deficient especially Potassium $\left(\mathrm{K}^{+}\right)$, Calcium $\left(\mathrm{Ca}^{++}\right)$and Magnesium $\left(\mathrm{Mg}^{++}\right)$as macronutrients, and iron $\left(\mathrm{Fe}^{++}\right)$as a micronutrient [7], therefore, chelated iron is added to the system in order to compensate for the lack [3]. Nevertheless, some farmers use some supplements to regulate both nutrient deficiencies and $\mathrm{pH}$ such as calcium and potassium hydroxides for increasing $\mathrm{pH}$ and phosphoric acid to reduce it.

Given the fact that fish feed is the main source of nutrients, we can consider it as a key element for aquaponics. However, one main challenge of aquaponics is to manage nutrient concentrations to promote optimal plant growth without causing any adverse effects on fish and bacteria.

\subsubsection{Water quality}

Water isthe matrix through which plants receive nutrients, and the medium in which both fish and bacteria live. In RAS, good water conditions are necessary for plant development [3]; since aquaponics is a branch of RAS, these systems bound to the same water quality parameters of recirculation aquaculture systems [22].

Aquaponics water quality requires balancing tolerance ranges of three groups of organisms for each water quality parameter; in general, the tolerance ranges of the three organisms are similar [12], however, optimising one unit comes at the expense of the other.

$\mathrm{pH}$ has a significant role in aquaponic systems functioning. It is an important water parameter that can affect either positively or negatively plant, fish and bacteria well-being. These three living organisms have different optimal $\mathrm{pH}$ ranges [7]. [23] recommend an acid $\mathrm{pH}$ for an optimum plant growth (5.5-5.8) [23], while nitrifying bacteria requires a neutral $\mathrm{pH}$ range (7.5-8) according to [19]. Fish optimal $\mathrm{pH}$ range varies depending on fish species, in general, RAS systems maintain $\mathrm{pH}$ between 7.0 and 8.0 [24-25]. Acidic $\mathrm{pH}$ yields to an optimal plant growth [26], on the other hand, it inhibits bacterial functioning and increase fish mortality [7-27], therefore, a neutral $\mathrm{pH}$ range of 7-9 is recommended for aquaponic systems [3-6-7-19]. The figure below (Fig.1) represents the operational $\mathrm{pH}$ for aquaponics systems according to [25]. 


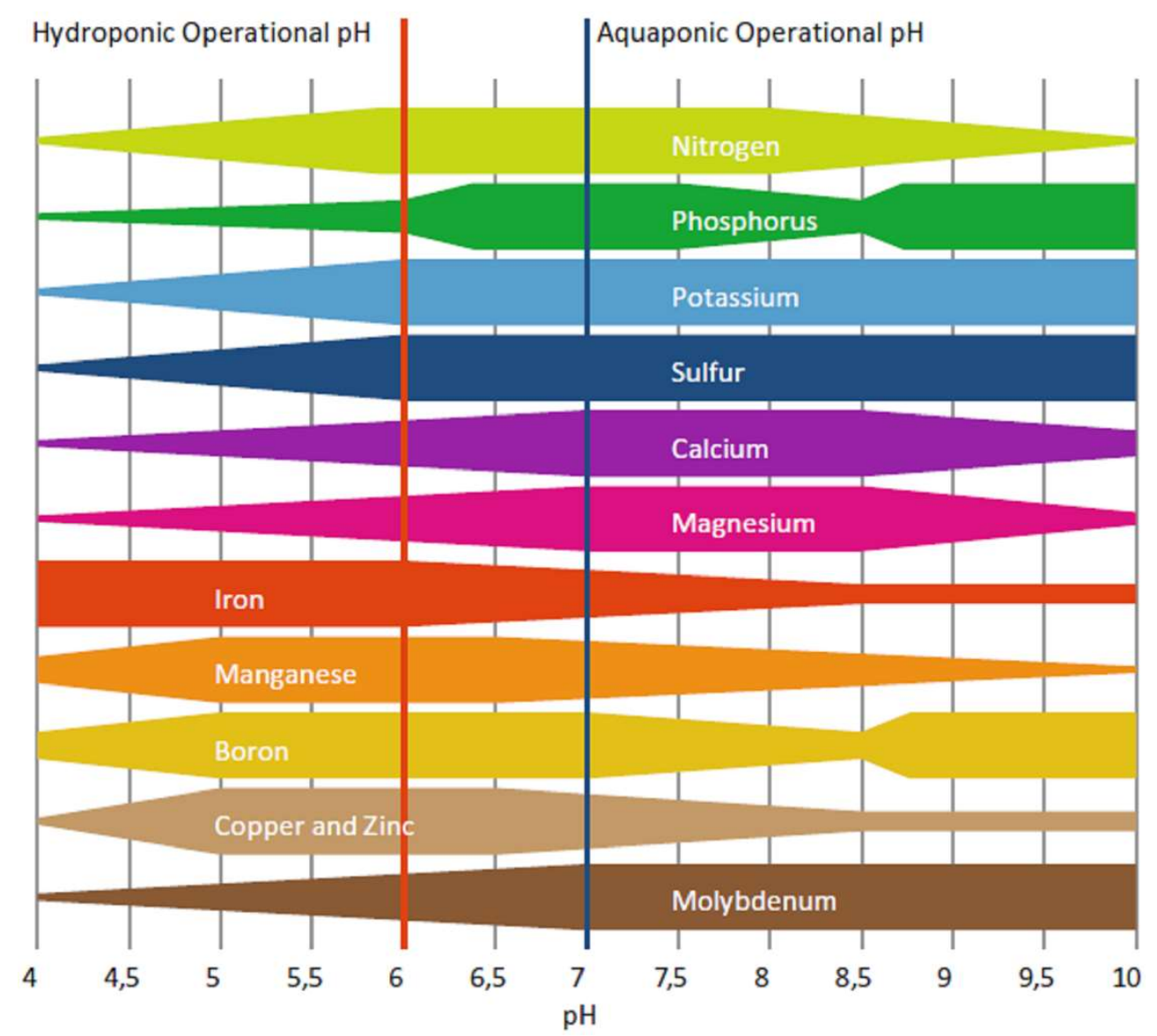

Fig. 1. Aquaponic operational $\mathrm{pH}$ and nutrient availability [25].

Dissolved Oxygen (DO) is another key water quality parameter for aquaponics. DO must be maintained in aquaponic systems [21-25]; considering that plant and nitrifying bacteria have lower DO requirements than fish [25], DO must be maintained depending on fish species. In general, warm water fish species can tolerate lower DO concentrations than cool water species [25], thus, DO concentration should be maintained at 5 ppm (parts per million) or higher. There is a negative correlation between water temperature and oxygen solubility, therefore, water temperature can affect aquaponics productivity [12]; however, water temperature is maintained in aquaponics depending on fish species requirements. [25] correctly argues that water-carbon dioxide $\left(\mathrm{CO}_{2}\right)$ is another important water quality parameter that is often ignored in aquaponic systems. Because the fish tolerance is generally lower than plants and bacteria [25], carbon dioxide concentration should be set according to fish requirements; [9] claims that carbon dioxide concentrations should be kept under $20 \mathrm{mg} / \mathrm{l}$ in RAS systems, which is, in general, the same case for aquaponics.

Total nitrogen (Ammonia, Nitrite, Nitrate) is a significant water quality parameter [12]. Nitrogen is essential for plants at all stages of vegetation (growth, reproduction, and storage), primordial for plant growth and well-being, the basis of all proteins. It is involved in proteins, nucleic acids and chlorophyll production [20-28]. In aquaponics, fish waste (gill excretion, urine and faeces) and fish food residue are the main source of Total Ammonia Nitrogen "TAN" [19]. Fish excreta (urine and faeces) contain 10 to $40 \%$ of nitrogen as ammonia [29].Nitric nitrogen, also called Nitrate $\left[\mathrm{NO}_{3}{ }^{-}\right]$, is the most soluble form and 
mainly used by plants. Ammonium $\left[\mathrm{NH}_{4}^{+}\right]$is also used but in small quantities, most of it is oxidised into nitrate by nitrifying bacteria. Organic nitrogen is indirectly usable; it undergoes mineralisation which will first produce ammoniacal nitrogen and then Nitric nitrogen. The main source of nitrate in aquaponic systems is nitrification process [3]; Nitrifying bacteria oxidise toxic forms of nitrogen excreted by fish, which is ammonia, into a non-toxic absorbable form by plants, which is nitrate [30]. The nitrification process is consisted of two dependent steps; first, ammonia oxidising bacteria convert ammonia[ $\left[\mathrm{NH}_{3} / \mathrm{NH}_{4}^{+}\right]$into nitrites $\left[\mathrm{NO}_{2}^{-}\right]$which in turn is used by nitrite oxidising bacteria to produce nitrates[ $\left.\mathrm{NO}_{3}{ }^{-}\right][21]$. Build-up solids provide although another part of nitrate through uneaten food mineralisation [7]. Nitrate is harmless for Aquaponic living components at concentrations of $150-300 \mathrm{mg} / 1$ [31-32]. Nitrite is more toxic than ammonia, above $1 \mathrm{mg} / \mathrm{l}$, it can be harmful for both plants and fish species and can cause the lethal Brown-blood disease for aquatic organisms [33]. Therefore, it is not recommended to add fish and plant during the cycling process.

Other water quality parameters that should be maintained are water clarity and water alkalinity. Suspended solids can affect both fish and plants well-being [21-24-25]; thus, suspended solids loads should be maintained below 30mg/1 [25]. Water alkalinity, also called carbonate hardness $(\mathrm{KH})$ is a key parameter due to its unique relationship with $\mathrm{pH}$ [12]; it is the total amount of carbonates $\left(\mathrm{CO}_{3}{ }^{2-}\right)$ and bicarbonates $\left(\mathrm{HCO}_{3}{ }^{-}\right)$dissolved in water. Carbonate Hardness buffer the $\mathrm{pH}$ (create resistance to $\mathrm{pH}$ change), therefore, the optimum level of alkalinity for aquaponics is about $60-140 \mathrm{mg} / 1$ [12].

Fish unit is the most sensitive among the three units. Fortunately, nitrifying process conditions matches perfectly fish species, while plant can tolerate it, therefore, aquaponics water quality parameters should be adapted to fish requirements.

\subsection{Aquaponic systems}

In general, an aquaponic system is consisted of a fish farming unit, a solids removal unit, a biofilter, a hydroponic unit and a sump [21]; in some systems, the hydroponic component, the biofilter and the solids removal component can be combined, such as media bed and deep water culture techniques.

There are generally three types of hydroponic subsystems: media bed culture, Nutrient Film Technique "NFT", and Deep Water Culture technique "DWC" [3-7-19-21]. Many experiments carried out by several researchers were able to test the three systems; as result, most of them agreed that NFT systems are the least productive among the three systems. [34] tells us cucumber culture yields in media bed are better than NFT's [34]. Another study by [35] tested the difference between the three hydroponic subsystems using an aquaponic system coupling Murray Cod with green oak lettuce; this study shows that NFT is less efficient in terms of removing nutrients from fish tanks effluent water and producing plant biomass or yield than media bed culture or DWC in an Aquaponic context. This approach was explained by the difference between plant roots contact with water in NFT (only half submerged in water) which makes the contact surface smaller comparing to DWC technique which provides more contact surface between plant roots and water.

Media bed culture technique is used mostly in small scale aquaponics dedicated to research experiments or small operations [7-12-21]. Media bed culture advantages include its simplicity and low initial costs [12]; this hydroponic system combines biological and mechanical filters with hydroponics which eliminates the expense of separate filters [21]. Another advantage of this system is that media act as a substrate for nitrifying bacteria [35] providing them more surface material for growth and nitrifying process [7-36]. This technique uses inert solids as a substrate such as gravel, hydroton, perlite, cocopeat, and sand [7-21] which provide a fixation substrate for plants root, offering a chance to grow 
larger plants. On the other hand, this technique has drawbacks such as high coasts when it comes to a larger scale [12], water channelling, inefficient biofiltration, inefficient nutrient delivery to plants and clogging of the media [7-12-35-37-38] if aquaculture unit effluent exceeds hydroponics' carrying capacity.

Deep water culture "DWC" also called floating or raft hydroponics is the best system design for commercial scale. It consists of suspending plants in polystyrene sheets, with their roots fully submerged in water [12]. Some of DWCs' benefits are their low maintenance, maximised nutrient uptake by plants and ability to support a large number of plants with minimal materials [7-39]. That's not all, DWC plants can support power outage up to two weeks [38], use only $1 \%$ of total water per day [40] and have lower environmental impact than media bed culture [7-41]. However, this technique requires a good oxygenation [12] and roots exposure to harmful organisms associated with aquaculture systems [21] such as fish fry and zooplankton.

There are two types of aquaponics systems: Coupled and decoupled systems. Coupled systems (Fig.2) are the classic systems of aquaponics, largely practiced in the USA, based on combining three classes of living organisms: Aquatic organisms, plants and bacteria taking advantage of each other. These systems consist of one recirculated closed loop, consisted of one or more fish tanks, a clarifier, a biofilter and a hydroponic unit [42], in which water flows over one outlet in each unit [7].

Water Flow by Gravity



Fig. 2. Basic technical system design of a coupled aquaponic system [42].

Water flows from the fish tank by gravity to a water treatment unit consisted of a sedimenter or a clarifier and a biofilter, then to a hydroponic unit. A sump is used in order to pump the water back to the fish tanks. Some designs of hobby scale aquaponics dispense the use of a water treatment unit and a sump such as media bed culture techniques, in which the media gravel plays a dual role, of both mechanical and biological filters, and the water is pumped from the fish tanks directly to the hydroponic unit and flows back to the fish tanks by gravity.

Modern aquaponics systems are adapting Decoupled system designs that are more complex but also more efficient (in terms of harvest yield and water and nutrient use efficiency) than coupled aquaponics systems. These designs separate the aquaculture unit from the rest of the system [43], in which water have more than one direction in some units [7]. Decoupled systems offer an efficient filtration and better control of nutrient concentrations and water $\mathrm{pH}$ [44-45-46]. Furthermore, these designs extract nutrients from the sludge and provide it to the plants in a soluble mineral form [43]. However, decoupled aquaponics systems remain complex and not are not practised enough yet, in addition to their high initial cost comparing to coupled designs. 


\subsection{Aquaponics profitability}

Until now, scientific publications on aquaponics generally dealt with the technical aspect, there are very few researchers who have studied the economic feasibility of aquaponics projects especially on a commercial scale. Aquaponics is generally profitable [37-47-48-49$50]$, it is a viable and sustainable food production technology. It is complex to calculate an aquaponics systems cost or to compare it to another system, this is due to the differences between specific site conditions, climatic factors, market prices, etc. These factors differ from region to region and from country to country. Energy cost is one of the highest costs in aquaponics systems [19-51], this parameter varies between countries, which makes the very valid point that studying aquaponics profitability is complex. [52] claims that aquaponics systems reach financial equilibrium after 2 yearswhile [19] correctly argues that aquaponics systems profitability should be calculated per square meter.

A financial feasibility study by [50] in a Mediterranean urban context found that aquaponics is profitable after an annual operating positive income, illustrating that labour is the main cost item of their system $(50 \%)$, however, this study was limited in a small scale system (a five square meter unit of one cubic meter fish tank). Given the fact that nutrients main source in aquaponics systems is fish feed, it seems to be one of the highest cost in this technology. Another study by [51] chose to focus on a small scale aquaponics system, to produce tilapia and a variety of crops products by adopting FAO model in order to evaluate its economic sustainability. This study tells us that greenhouse construction cost, fingerlings, and energy cost are the main costs of aquaponics systems, however, they correctly argue that horticultural profitability would be higher if they focused on crops with short production cycle such as lettuce. In a point of view economic profit, this system was non-profitable, the authors suggest that small scale aquaponics should be utilised for autonomy and self-consumption.

One of the limitations with aquaponics development is the lack of commercial scale financial feasibility, considering that private companies do not share their studies with the public, while those scientific experiences are limited to small scale systems.

\section{The contribution of Aquaponics to Moroccan development}

\subsection{Moroccan aquaculture}

In nearly 100 years, Moroccan aquaculture started. The first freshwater fish farming activity has begun with the creation of the first fish hatchery in Azrou, which aimed to promote recreational fishing through restocking lakes in the Middle Atlas [53]. Freshwater aquaculture has turned, since the $80 \mathrm{~s}$, from a restocking activity into a food production aquaculture, through the creation of multiple private units practicing eel, carp, tilapia and trout farming, and exploiting the dams for public extensive aquaculture activities [54]. Freshwater aquaculture production is estimated at 15,000 tonnes in 2015 , divided into 13,000 tonnes of restocking and 2,000 tonnes of intensive production. The 90 s were the most productive years of Moroccan aquaculture. During this period, Morocco has benefited from FAO assistance within the framework of the Technical Cooperation Programme (TCP). In the late 90s, multiple shellfish farming companies were installed on the Atlantic coast practicing St. Jacques shells, mussels, oyster and clam farming [53-55]. Therefore, Moroccan aquaculture recorded its peak production in 1999, with 2793 tonnes [53]. On the other hand, the 2000s were critical for the Moroccan aquaculture sector. Multiple problems accumulation led to a significant decline in national production. Most of mariculture companies have marketed their products in the European market, however, European health measures were the origin of the quantity limitation produced of bivalves [55], likewise, the 
European market knew a price drop of aquaculture products explained by public aid from the European Union to European aquaculture farms. On the other hand, some companies closed due to financial issues, while MAROST was forced to close due to European competition. Marine aquaculture has suffered from environmental problems such as the appearance of phytotoxins in the Mediterranean, and the degradation of the Atlantic lagoons [55].

Since 2009 , the kingdom has decided to move towards the blue economy and this by adopting a strategy which encourages development and enables sustainable and reasonable competitiveness in the national fishing sector, baptised Halieutis. Actually, marine aquaculture produces 600 tonnes according to [1], which is considered negligible compared to national fishery production (1.37 million tonnes).

Moroccan Aquaculture is still between hypes and hopes, suffering from several problems such as inexistence of hatcheries of marine products and good quality fish feed producers, high competition from European and Asian productions, lack of product diversification, especially marine products, which remain limited to Sea bass, Sea bream, Oysters and Clams, and the absence of a common administrative framework which inhibits the sustainable development of the sector.

\subsubsection{Framework of inland aquaculture}

The management and promotion of freshwater aquaculture is attributed to the Department of Water and Forests (DEF) of the Ministry of Agriculture, Fisheries, Rural Development, Water and Forests. Inland aquaculture is governed by the Dahir of April 11, 1922 and its texts taken for its application. The Department has succeeded until today in developing inland aquaculture by implementing a development strategy (2005-2014) for fishing and fish farming in continental waters [53], which helped inland production to jump from 2500 tonnes in 2005 to 15000 tonnes in 2014. National Center for Fish and Hydrology in Azrou (CNHP) of the High Commission for Water, Forests and Desertification Control is invested in the Research and Development mission; its role is restocking dams essentially. The mission of this center is to generate knowledge and appropriate technologies to enhance the aquatic environment, create jobs and contribute to the development and promotion of continental aquaculture. In 2015, DEF has set another pivotal strategy (2015-2024) who aims to enhance inland production to reach 50000 tonnes by 2024 and to create 10000 aquaculture jobs [54], through the adoption of advantageous fiscal measures, such as reduction of the import tax on feed for aquaculture.

Actually, there are five hatcheries (three public and two private) and seven breeding stations including two Eel culture farms, four Tilapia farms and only one Trout farm. Compared to marine aquaculture, inland farming is playing a significant role in the development of the aquaculture sector, and that's by mastering freshwater species production steps, however, the marketing of its products remains modest given the weak demand of the national market. The favourable climate of the kingdom, its 3,500 km long coastline and 120,000 ha underexploited massive freshwater resources, are potentials to increase national aquaculture production levels in both marine and freshwater.

\subsubsection{Fish species with aquaponics potential}

There are six major families reared in Moroccan inland aquaculture: Anguillidae, Centrarchidae, Cichlidae, Cyprinidae, Esocidae, and Salmonidae, both native and nonnative fresh water species are reared. 
- Anguillidae family is represented by the European eel Anguilla Anguilla (Linnaeus, 1758), an endemic species with a high commercial value, purely economic breeding intended for export to Asian and European countries.

- Centrarchidae family is represented by the largemouth bass Micropterus salmoides, (Lacépède, 1802), a non-native species also known as The black bass, of North American origin, which found its ideal in the Moroccan climate.

- Cichlidae family is represented by the Nile tilapia Oreochromis niloticus, (Linnaeus, 1758), of North African origin, introduced from Egypt, known for its resistance and rapid growth, widely practiced in breeding.

- The common carp or European carp Cyprinus carpio, (Linnaeus, 1758), is a nonnative species of the Cyprinidae family, widely introduced to lakes for sport fishing. The grass carp Ctenopharyngodon idella and the silver carp Hypophthalmichthys molitrix are another species of Cyprinidae family, of East-Asian origin, largely introduced to Moroccan dams for aquatic weed control.

- The northern pike Esox Lucius, (Linnaeus, 1758) is the Esocidae family representative, a brackish carnivorous species introduced to Morocco for sport and commercial fishing.

- Salmonidae family is represented by two important species, a native species which is the brown trout Salmo trutta macrostigma, and the rainbow trout Oncorhynchus mykiss which was introduced in Morocco since 1924.

So far, Moroccan native species are rarely reared despite having good economic potential. Taking for example some species of trout: Salmo akairos which is a trout species that inhabits Ifni lake of the Atlas Mountains, and Salmo multipunctata a new species of Atlantic trout identified in 2015 [56] that inhabits Draa basin in southern Morocco. These species inhabit cold freshwater water streams, these habitats suffer catastrophic seasonal floods that affect the demography of the populations; The deforestation of the Atlas Mountains and overfishing are the main problems that affect trout species in Atlas Mountains, therefore, these species, that are considered endangered, need to be reared for economic and environmental reasons, otherwise, Salmo pallaryi, another trout species of Atlas Mountains which populated Sidi Ali Lake, is probably extinct.

The blue barbell Pterocapoeta maroccana (Günther, 1902) is a native species of Cyprinidae family, only found in Morocco, included in the IUCN category of endangered species since 2006. It's an omnivorous species that populate fast flowing streams [57]. Pterocapoeta maroccana is the only representative of the genus, threatened by barant net fishing, climate change, habitats destruction by pollution from the use of pesticides and fertilizers and household garbage. This species needs to be reared in order to repopulate its habitat, as a freshwater species, the blue barbell is a native species with aquaponics and aquaculture potentials.

\subsection{Socio-economic impact of Aquaponics in Morocco}

The Moroccan agricultural sector is one of the main sectors of activity at the national level, it is one of the pillars of the Moroccan economy. The share of agricultural upstream in the national economy is considerable with 74 billion dirhams, which corresponds to $14 \%$ of the gross domestic product [58-59].

Food insecurity in Morocco is a real threat to the nation and this is due to multiple causes; drought, water scarcity and other problems linked to climate change affect food production, hailstorms is one of them, this phenomenon threatens Moroccan agricultural production; A hailstorm hit the region of Fes-Meknes and affects crops on the previous sixth of June, the affected area could reach 9,100 hectares in 27 rural municipalities in the region (Ministry of Agriculture and Fisheries). These problems can lead to food insecurity 
in rural areas, it also can increase agricultural products prices, for this reason, rational food production technologies need to be practiced. Fish consumption increased up to $16 \mathrm{~kg} /$ year per capita in 2020 and demand is likely to increase further, and this is due to Moroccan population growth, furthermore, poverty is one of the main causes of inequality in food availability, especially in rural areas.

Local food production should cover local food demand in order to enable inhabitants of poor and / or arid regions, where water supply is relatively limited, to have access to a source of animal and vegetable protein; this is the major advantage of this activity and it is a support for food security. Aquaponics is a sustainable food production approach that uses $90 \%$ less water compared to aquaculture and agriculture [12], due to the minimal water loss represented by evaporation and transpiration from plants. Its strengths are represented by the fact that this activity eliminates the use of chemicals or pharmaceuticals which allows to produce more food with less resources, reduces negative impacts of Agriculture and Aquaculture on the environment (Organic and chemical pollutions), and according to some scientific publications aquaponics increases productivity compared to Hydroponics supporting food security. Furthermore, this activity fights against soil degradation, allowing environment conservation and restoration, which indirectly preserve Biodiversity.

\section{Conclusion}

The Moroccan economy is mainly based on two major food production sectors: Agriculture and sea fishing. Unfortunately, Moroccan agriculture is threatened by rising temperatures and lower rainfall, as well as fish products are overexploited. For this reason, sustainable agriculture and aquaculture are alternative solutions. Aquaculture should be practiced not only for its economic benefits, but also for its positive environmental impact which is biodiversity conservation. Moroccan native species are endangered and threatened, due to climate change, habitats degradation and overfishing; controlling reproduction and breeding of these species can be an effective solution for this threat to Moroccan biodiversity, and that's by repopulating natural habitats while exploiting these species rationally in aquaponics to grow vegetables. Today, the principal concern of Moroccan aquaculture should be rearing endemic species in order to repopulate natural habitats, while using aquaculture wastes for growing plants on aquaponics.

\section{Acknowledgements}

This study was supported by the MENFPESRS and CNRST from Morocco under grant $N^{\circ} P P R / 2015 / 1$ for the project "Impact des changements climatiques sur la diversité génétique des poissons des eaux douces du Maroc”.

\section{References}

[1]. Ministère de l'Agriculture, de la Pêche Maritime, du Développement Rural et des Eaux et Forêts, Département de la Pêche Maritime, La mer en chiffres (2019)

[2]. Ministère de l'Agriculture, de la Pêche Maritime, du Développement Rural et des Eaux et Forêts, Département de l'agriculture, Filières végétales, (2020). [Online]. Available: https://www.agriculture.gov.ma.

[3]. S. Diver, Natl. Sustain. Agric. Inf. Serv. 28:1-28 (2006)

[4]. D. Klinger and N. Rosamond, ARER37, pp. 247-76, (2012)

[5]. S. Goddek, C. R. Espinal, B. Delaide, M. H. Jijakli, Z. Schmautz, S. Wuertz and K. J. Keesman, Water8, pp. 303, (2016) 
[6]. Z. M. Gichana, D. Liti, H. Waidbacher, W. Zollitsch, S. Drexler and Waikibia Joseph, AI26, pp. 1541-1572, (2018)

[7]. B. Yep and Y. Zheng, JCP228, p. 1586-99., (2019)

[8]. T. Losordo , M. Masser and J. Rakocy, SRAC, (1998)

[9]. M. P. Masser, J. Rakocy and T. M. Losordo, SRAC, (1999)

[10]. N. Kasozi, R. Tandlich, M. Fick, H. Kaiser and B. Wilhelmi, AR15, (2019)

[11]. Z. Wu, S. Chunhua and v. d. H. Anton, PR90, p. 119-33, (2019)

[12]. C. Sommervile, M. Cohen, E. Pantanella , A. Stankus and A. Lovatelli, Small-Scale Aquaponic Food Production : Integrated Fish and Plant Farming, in : Fao Fisheries and Aquaculture Technical Paper 589, Rome, (2014)

[13]. L. C. Naegel, Aquaculture10, pp. 17-24, (1977)

[14]. B. König, J. Janker, T. Reinhardt, M. Villarroel and R. Junge, JCP180, pp. 232-243, (2018)

[15]. H. M. Vines and R. T. Wedding, PP35, p. 820-825, (1960)

[16]. J. B. Jones, Hydroponics : A Practical Guide for the Soilless Grower, 2nd ed., Boca Raton: CRC Press, (2005)

[17]. S. J. Leghari, N. A. Wahocho, G. M. Laghari, A. H. Laghari, G. M. Bhabhan, K. H. Talpur, T. Ahmed, S. A. Wahocho and A. A. Lashari, AEB10, pp. 209-219, (2016)

[18]. J. W. Salisbury and D. M. D’Aria, RSE46, pp. 83-106, (1992)

[19]. S. Goddek, B. Delaide, U. Mankasingh, K. V. Ragnarsdottir, H. Jijakli and R. Thorarinsdottir, Sustainability7, pp. 4199-4224, (2015)

[20]. A. McCauley, C. Jones and J. Jacobsen, NMM, p. 11-12, (2009)

[21]. J. Rakocy, M. P. Masser and T. Losordo, SRAC, (2006)

[22]. C. Espinal and D. Matulic, Recirculating Aquaculture Technologies, in : S.Goddek, A.Joyce, B.Kotzen, G.M.Burnell, Aquaponics Food Production Systems: Combined Aquaculture and Hydroponic Production Technologies for the Future, pp. 35-76, (2019).

[23]. B. Bugbee, AH , pp. 99-112, (2004)

[24]. M. B. Timmons, J. M. Ebeling, F. Wheaton, S. Summerfelt and B. Vinci, Cayuga Aqua Ventures, LLC., (2002)

[25]. W. Lennard and S. Goddek, Aquaponics : The basics, in : S.Goddek, A.Joyce, B.Kotzen, G.M.Burnell, Aquaponics Food Production Systems: Combined Aquaculture and Hydroponic Production Technologies for the Future, pp. 113-143, (2019)

[26]. Y. Zou, Z. Hu, J. Zhang, H. Xie, C. Guimbaud and Y. Fang, BT 210 , p. 81-87, (2016)

[27]. R. V. Tyson, E. H. Simonne, D. D. Treadwell, J. M. White and A. Simonne, HS 43, pp. 719-724, (2008)

[28]. R. Novoa and R. Loomis, PS 58, pp. 177-204, (2005)

[29]. S. Wongkiew, Z. Hu, K. Chandran, J. Woo Lee and S. K. Khanal, AE 76, pp. 9-19, (2017)

[30]. D. E. Canfield, A. N. Glazer and P. G. Falkowski, Science, 330, pp. 192-196, (2010)

[31]. A. Graber and R. Junge, Desalination246, pp. 147-156, (2009)

[32]. W.-H. Hu, L. C. Cajas-Monson, S. Eisenstein, L. Parry, B. Cosman and S. Ramamoorthy, NJ 14, p. 91, (2015)

[33]. M. B. Timmons and J. M. Ebeling, Cayuga Aqua Ventures, LLC $2^{\text {nd }}$ edition, (2010)

[34]. S. Wren, Comparison of hydroponic crop production techniques in a recirculating fish culture system, Texas A\&M University, College Texas, Texas, (1984)

[35]. W. A. Lennard and B. V. Leonard, AI 14, pp. 539-550, (2006) 
[36]. C. Maucieri , A. A. Forchino, C. Nicoletto, R. Junge, R. Pastres , P. Sambo and M. Borin, JCP 172, pp. 3119-3127, (2018)

[37]. J. Rakocy, D. Bailey, K. Shultz and W. Cole, Evaluation of a Commercial-Scale Aquaponic Unit for the Production of Tilapia and Lettuce, in : Tilapia In Aquaculture106, 357-372(1997)

[38]. J. Rakocy, Aquaponics $Q$ and A (The Answers to Your Questions About Aquaponics), Nelson and Pade, Inc. (2003)

[39]. D. Patillo, NRAC Technical Bulletin Series 19, pp. 1-10, (2019)

[40]. D. C. Love, M. S. Uhl and L. Genello, AE 68, pp. 19-27, (2015)

[41]. Forchino, H. Lourguioui, D. Brigolin and R. Pastres, AE 77, pp. 80-88, (2017)

[42]. H. W. Palm, U. Knaus, S. Appelbaum, S. M. Strautch and B. Kotzen, Coupled Aquaponics Systems, in : S.Goddek, A.Joyce, B.Kotzen, G.M.Burnell, Aquaponics Food Production Systems: Combined Aquaculture and Hydroponic Production Technologies for the Future, pp. 163-199, (2019)

[43]. S. Goddek and O. Körner, AS 171, pp. 143-154, (2019)

[44]. W. Kloas, R. Gross, D. Baganz, J. Graupner, H. Monsees, U. Schmidt, G. B. Staaks, J. Suhl, M. Tschirner, B. Wittstock, S. Wuertz, A. Zikova and B. Rennert, AEI7, pp. 179-192, (2015)

[45]. S. Goddek and K. J. Keesman, Desalination 428, pp. 76-85, (2018)

[46]. S. Goddek and K. J. Keesman, AI 28, pp. 2481-2490, (2020)

[47]. J. Rupasinghe and J. Kennedy, AEM 14, pp. 81-96, (2010)

[48]. K. Tokunaga, C. Tamaru, H. Ako and P. Leung, JWAS46, pp : 20-32(2015)

[49]. K. K. Quagrainie, R. Valladão Flores, H.-J. Kim and V. McClain, Economic Analysis of Aquaponics and Hydroponics Production in the US Midwest, JAA 30, pp : 114(2017)

[50]. A. Ascuito , E. Schimmenti, C. Cottone and V. Borsellino, UFUG 38, pp. 397-402, (2019)

[51]. J. Lobillo-Eguíbar, V. M. Fernández-Cabanás , L. A. Bermejo and L. PérezUrrestarazu, Agronomy10, p. 1468, (2020)

[52]. R. Laviale, (2015)

[53]. FAO, Vue Générale Du Secteur Aquacole National - Maroc, (2015). [Online]. Available: https://www.fao.org/fishery/countrysector/naso_morocco/fr.

[54]. REAPC, Etude préliminaire sur l'aquaculture au Maroc, 72, (2016).

[55]. FENIP, Etude de l'état des lieux de l'aquaculture au Maroc et identification des marchés aquacoles cibles et de leurs conditions d'accés, Juillet, (2010)

[56]. Doadrio, s. Perea and A. Yahyaoui, Graellsia71, pp. 1-26, (2015)

[57]. A. Yahyaoui, S. Perea, P. Garzon and I. Doadrio, Atlas des poissons des eaux continentales du Maroc, (2019)

[58]. The World Bank, Rapport de suivi de la situation économique au Maroc, (2020)

[59]. HCP, Prospective Maroc 2030 _ Agriculture 2030, quels avenirs pour le Maroc, (2011) 